\title{
Colletrotrichum gloeosporioides causando antracnose em frutos de pupunheira nos estados de Minas Gerais e Paraná
}

\author{
João Batista Vida ${ }^{1}$, Dauri José Tessmann ${ }^{1}$, Rudimar Mafacioli'1 ${ }^{1}$ Jaqueline Rosemeire Verzignassi ${ }^{1,2}$, Álvaro Figueredo \\ dos Santos ${ }^{3}$
}

\begin{abstract}
${ }^{1}$ UEM - Universidade Estadual de Maringá, Departamento de Agronomia, Av. Colombo, 5790, 82020-900, Maringá - PR. jbvida@uem.br
${ }^{1,2}$ Pesquisadora Capes/PRODOC. jrverzignassi@uem.br; ${ }^{3}$ Embrapa Florestas - Colombo - PR. Bolsista do CNPq.

Data de chegada: 08/11/2004. Aceito para publicação em: 26/09/2005.
\end{abstract}

\begin{abstract}
Vida, J.B., Tessmann, D.J., Mafacioli, R., Verzignassi, J.R., Santos, A.F. dos. Colletrotrichum gloeosporioides causing anthracnosis on peach palm fruits in Minas Gerais and Paraná States, Brazil. Summa Phytopathologica, v.32, n.4, p.379-380, 2006.

The cultivation of peach palm (Bactris gasipaes) for production of palm heart has increased in Southeast and Southern Brazil, in areas of domain of Atlantic Forest. Adult peach palm plants kept for seed production have suffered severe rot damages on fruits, resulting from coalescence of

spots. The fungus Colletotrichum gloeosporioides was isolated from the damaged tissues and its pathogenicity to peach palm fruits was confirmed under controlled conditions. This is the first report of this disease damaging peach palm fruits in the Minas Gerais and Parana States.

Additional keywords: Bactris gasipaes, peach palm.
\end{abstract}

\section{RESUMO}

Vida, J.B., Tessmann, D.J., Mafacioli, R., Verzignassi, J.R., Santos, A.F. dos. Colletrotrichum gloeosporioides causando antracnose em frutos de pupunheira nos estados de Minas Gerais e Paraná. Summa Phytopathologica, v.32, n.4, p.379-380, 2006.

O cultivo de pupunha (Bactris gasipaes) para palmito tem-se expandido para algumas regiões do Sudeste e Sul do Brasil, ocupando áreas abandonadas pela agricultura no espaço territorial de domínio da Mata Atlântica. Em plantas adultas de pupunheira, cultivadas para a produção de sementes nos estados de Minas Gerais e Paraná, verificou-se ocorrência de antracnose nos frutos, causando severa podridão. O fungo Colletotrichum gloeosporioides foi isolado de tecidos doentes e a sua patogenicidade aos frutos da pupunheira foi confirmada em condições controladas. Essa foi a primeira constatação da doença em frutos nos estados de Minas Gerais e Paraná.

Palavras-chave adicionais: Bactris gasipaes, podridão-do-fruto.

Na última década, o extrativismo destrutivo das palmeiras juçara (Euterpe edulis Mart.), na região de domínio da mata atlântica e do açaí (E. oleracea Mart.), na Amazônia, como também a necessidade de sistemas de produção alternativos e permanentes têm gerado um cenário favorável para ações de produção de palmitos cultivados no Brasil (1). Por outro lado, o cultivo de palmeiras com características de rusticidade, perfilhamento, precocidade e que produzem palmito de boa qualidade, como a pupunheira (Bactris gasipaes Knuth) tem tido alta preferência pelos agricultores (1). Em várias regiões brasileiras dos estados da Bahia, São Paulo, Minas Gerais, Paraná, Espírito Santo, Tocantins e da Amazônia têm-se verificado a instalação de médios e pequenos plantios de pupunheira (1).

As sementes de pupunheira apresentam preço elevado e a maior parte é importada do Peru, sendo o restante produzido na região Amazônica. Com a finalidade de avaliar a viabilidade da produção de sementes, algumas áreas de observação foram instaladas em Patos de Minas-MG e Cidade Gaúcha-PR. Em visitas aos cultivos de pupunha nestas regiões foram coletados vários cachos de plantas matrizes, com os frutos maduros e apresentando manchas. As manchas, inicialmente eram pequenas, deprimidas, de coloração clara e formato arredondado. Num estádio mais avançado da doença, as manchas aumentavam de tamanho, atingindo diâmetro de até três centímetros e eram cobertas por abundante massa de esporos, de aspecto mucilaginoso e de coloração rósea-clara. Seccionando-se os frutos observou-se que as manchas também se estendiam para o seu interior. Quanto maior o diâmetro externo das manchas, maior era a sua profundidade nos frutos, muitas vezes se estendendo até às sementes. Quando ocorriam várias manchas num mesmo fruto, observou-se a sua coalescência, resultando em podridão generalizada da polpa dos frutos. Em estádio mais avançado da colonização, as manchas tornavam- se enegrecidas, com coloração negra intensa, devido ao desenvolvimento de outros fungos saprófitas (Figura 1).

As amostras de frutos foram encaminhadas ao laboratório de fitopatologia da Universidade Estadual de Maringá, onde foram 

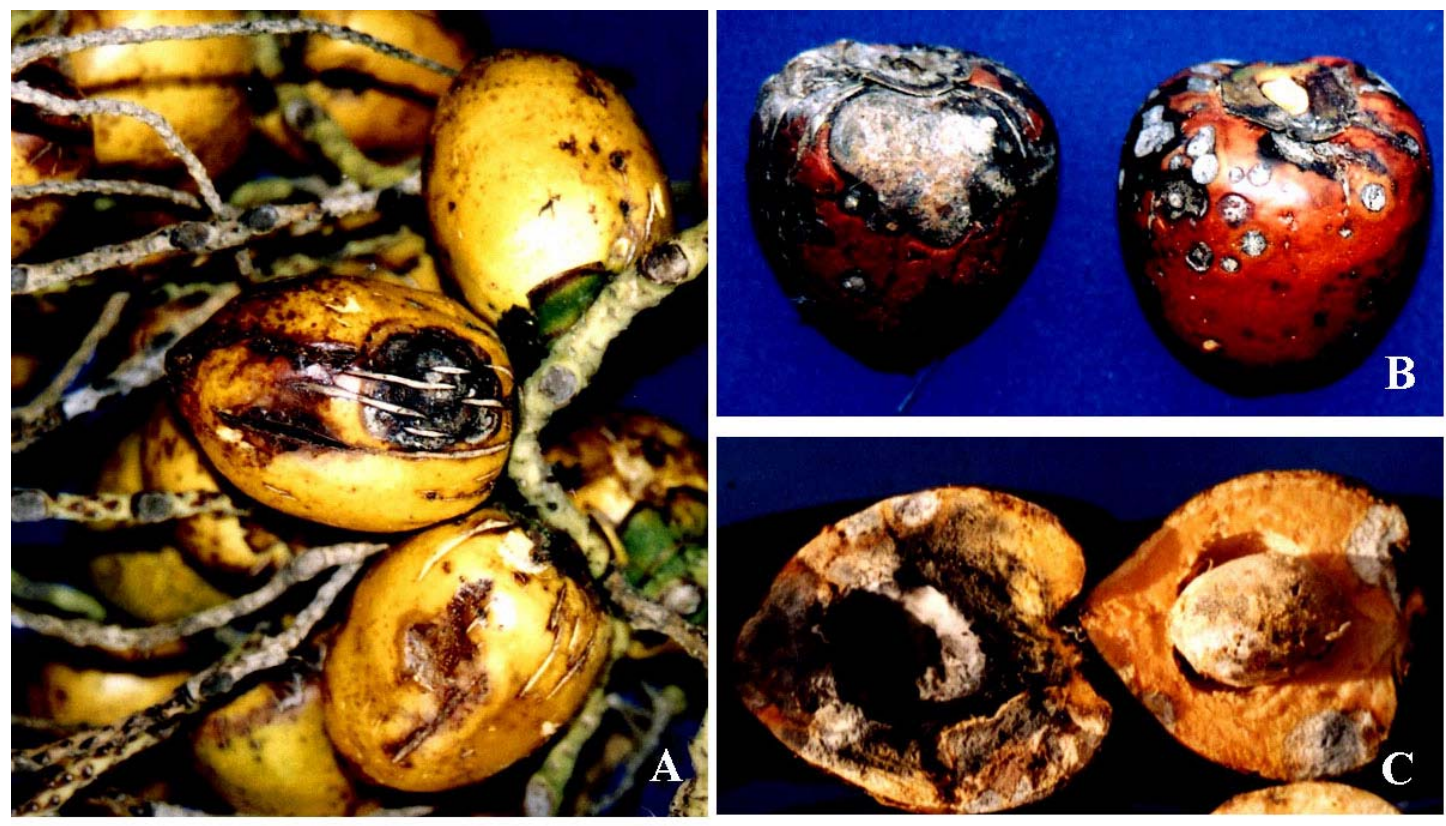

Figura 1. Antracnose (Colletotrichum gloeosporioides) em frutos de pupunheira. Sintomas superficiais (A e B) e sintomas profundos (C).

efetuadas preparações a fresco dos sinais de um fungo presente nas manchas, seguindo-se de observações ao microscópio óptico (MO). Em seguida, procedeu-se ao isolamento do fungo presente nas manchas em cultura pura, em meio de cultivo BDA. Após crescimento micelial e esporulação, realizaram-se novamente preparações a fresco e observações ao MO. Identificou-se Colletotrichum gloeosporioides (Penz.) Sacc. como o fungo presente e associado aos sintomas de manchas nos frutos (2). A patogenicidade de C. gloeosporioides foi confirmada após inoculação de frutos destacados maduros e sadios de pupunheira. Os sintomas da antracnose desenvolveram-se nos frutos inoculados, com produção de conídios de C. gloeosporioides.

A antracnose, causada por C. gloeosporioides, foi relatada na Amazônia, infectando folhas de pupunheira e causando queda prematura de frutos (3). Na Região Sul do Brasil, a antracnose foi constatada como a principal doença da pupunheira, mas infectando somente as folhas de plantas novas (4). Até então, ainda não havia sido relatado infecção em frutos.

\section{REFERÊNCIAS BIBLIOGRÁFICAS}

1. Kulchetscki, L.; Chaimsohn, F.K.; Gardingo, J.R. Palmito pupunha (Bactris gasipaes Kunth): a espécie, cultura, manejo agronômico, usos e processamentos. Ponta Grossa: Editora UEPG, 2001. 148p.

2. Mafacioli, R. Caracterização morfo-fisiológica e patogênica de isolados de Colletotrichum gloeosporioides da pupunheira (Bactris gasipaes). 2002. 80f. Dissertação (Mestrado em Agronomia) Universidade Estadual de Maringá, Maringá.

3. Mota, A. M.; Gasparotto, L. Dinâmica da queda precoce de frutos de pupunheira. Fitopatologia Brasileira, Brasília, v.20, suplemento, p.337, 1995.

4. Santos, A.F.; Tessmann, D.J.; Nunes, W.M.C.; Vida, J.B.; Jaccoud Filho, D.S. Doenças foliares da pupunheira (Bactris gasipaes) no Estado do Paraná. Boletim de Pesquisa Florestal, Curitiba, v.42, p.125-130, 2001. 